\begin{abstract}
- one death did not seem to be materially benefited. One of these cases, to which I was called to see on the twelfth day of the disease, running the regular course of not less than thirty-five days after seeing her, at which time the Woodbridge treatment was instituted. The treatment was left off after twenty days in this case, not seeming to produce any benefit, and the patient treated symptomatically. In all cases ptyalism can be prevented by using a tooth powder of potassium chlorate once daily, which destroys the

ber of years. The frequency of administration of doses at first does not disturb the patient so much as one would suppose, if so after 10 P.M. I would give a double dose of number one every half hour until morning.

In conclusion I would say that Dr. James Jackson, of Boston, advocated the use of gastric lavage a number of years ago, especially in the first stages of the disease and thought it could be aborted in some cases by its prompt use.
\end{abstract} microorganisms around the roots of the teeth which are especially active while the system is loaled with mercury, and is the cause of ptyalism. I think the mercury in the prescription is very essential, as it assists in throwing off the effete material. I did not give a single dose of opium or astringent except in one case, and that the case in which I left treatment off after twenty days.

The eliminative action of calomel and rectal injections kept bowels open and prevented diarrhea, the results of the efforts of nature to get rid of the toxins of the disease. They would have under this treatment from four to six actions in the twenty-four hours, which is a thing urgently necessary, according to my judgment, in this disease. Only two had intestinal hemorrhages, one ending in death, and in these cases the rectal injections were left off. Several cases I was called to see which had already exhibited marked cases of tympanites were relieved of the latter by this treatment in a few days. I noticed that especially their nervous symptoms were alleviated by these antiseptics frequently administered, the gastro-intestinal tract being simply flooded. I do not feel so enthusiastic as Dr. Woodbridge does in thinking every case could be saved, but I do think that his treatment, in connection with sponge baths and rectal injections, an improvement over Brandt's one-sided bath, or someone else's exclusively medical treatment, notwithstanding Professor Osler's declaration that no known remedy shortens the disease by one single day.

Not a single dose of the coal-tar derivatives were given. Only the sponge baths and rectal injections of cold water, both of which I think quite necessary, being used to reduce temperature.

Dr. Peckham assured me, that according to his observation, the addition of the carbolic acid to the enema had no deleterious effect, and although I watched it carefully, could see none myself.

I think the stomach lavage a great assistance in the first stage of this disease, but not so essential as the rectal injections. The latter would reduce temperature without the acid, but once in a while a little of the acid would be absorbed, producing free prespiration, though no weakness. My results have not been so good as those of Dr. Woodbridge, perhaps my own fault, not being so familiar with the treatment, but were I to pass through another epidemic, I should certainly rely upon this as my sheet anchor, for seem. ingly in a number of cases the results were brilliant, although cognizant of the fact that not infrequently a case will start with severe symptoms and subside in a few weeks under symptomatic treatment. I saw in a number of cases of high morning temperature, an amelioration of symptoms under this treatment, and when I would experimentally leave off medicines the symptoms would be aggravated.

Dr. Woodbridge has simply carried to the fullest extent, in my judgment, the treatment advocated by some of the leading men of the profession for a num-

\title{
IS HYSTERECTOMY FOR PUERPERAL INFECTION JUSTIFIABLE?
}

Read by title before the Southern Surgical and Gynecological Association.

BY R. R. KIME, M.D.

['RESIDENT OF ATLANTA OBSTETRICAL SOCLFTY; PRESIDENT OF ATI,ANTA MEDICAI, SOCIETY; VICE-PRESIDENT OF THE TRI-STATE MEDICAL SOCIETY OF GEORGIA, ALABAMA AND TENNESSEE; EXPRESIDENT EXPÓSITION HOSPITAL STAFF, ETC. ATIANTA, GA.

At the present time this is an important question and of interest to the medical profession in general. While asepsis and antisepsis have rendered incalculable service in the prevention of puerperal infection, such cases occur and we are compelled to devise means for their relief.

Before adopting any line of treatment or surgical measure in these cases, it should be established that they are life-saving commensurate with the risks incurred by their use.

Before hysterectomy can be adopted as a justifiable measure in puerperal infection it must be demonstrated that it will save lives that can not be saved by less heroic treatment.

From inquiry of eighteen leading gynecologists and obstetricians, I find five opposed and thirteen in favor of the operation.

Out of fifteen cases operated upon eight have died, making a death-rate of 531 per cent.

In most instances it is said that the operation is done as a last resort in severe cases, and with the oftrepeated remark, "the patient would have died without it." While this may be true, all of us have seen such patients get so low and yet recover that I have lost confidence in such positive prognoses.

The advocates of hysterectomy advise it for disease limited to uterine body, such as septic metritis, multiple abscesses in uterine wall, uterine thrombo-phlebitis, and gangrene of uterus.

Pyosalpinx, ovarian abscesses, etc., are the secondary localized results of puerperal infection, hence operations for such do not come within the scope of this paper.

The fact that a patient recovered from hysterectomy is not conclusive evidence that the operation was justifiable. A uterus filled with putrid material can be removed and patient recover in the great majority of cases, yet the condition does not justify such measures. The same can be said of all cases of putrid infection, for they can be relieved by less heroic measures and without sacrifice of pelvic organs. In septic infection when serious constitutional symptoms develop, the process in most cases is no longer local, and can not be removed by hysterectomy, the germs and septic material having extended beyond the uterus, tubes and ovaries into the blood vessels, lymphatics, pelvic cellular tissue, and the general circulation. In a few cases the process may be sufficiently local to justify hysterectomy, but to diagnose 
such a condition is a difficult task. None but an expert can do so, and they are frequently mistaken in diagnosis.

Most gynecologists that favor hysterectomy advise to curette and tampon uterus, and if the patient does not improve or grows worse then remove the uterus.

If this is a correct guide as to the indications for hysterectomy, then it is not a question of diagnosis, but failure in a certain line of treatment to give relief that demands the sacrifice of the uterus. In severe cases of septic infection to curette and tampon the uterus, then perform hysterectomy, the death-rate would be so high as to condemn the operation and many lives would be lost that could be saved by less heroic means.

To be more explicit, I will deviate from the title of this paper and enter briefly into the pathology and treatment of puerperal infection.

It is of two general varieties, viz.: 1. Putrid infection or sapremia. 2. Septic infection or septicemia.

The first is a local infection due to decomposition of the uterine contents by putrefactive bacteria only without migration of the bacilli, not contagious, nonprogressive by invasion, due to absorption of ptomaines not inoculable.

In sapremia, putrid infection, remove the putrid material from the uterine cavity, irrigate, disinfect, drain, and 99 per cent. of cases will recover. Hysterectomy would relieve these cases, but it would be criminal to sacrifice the generative organs when such cases can be treated more successfully and with fewer deaths by less heroic measures.

The second class is due to germ development, their rapid migration and invasion of new tissue even entering the general circulation; if at first local it soon becomes constitutional, highly infectious, and inoculable from case to case. The contagious principle is destroyed by boiling, putrefaction and germicides.

In the treatment of septic infection we have a more difficult problem to solve.

The septic germs soon extend beyond the endometrium, invading its muscular structures, the lypmphatics, the blood vessels, etc., and can not be removed by ordinary surgical measures, and it is very doubtful if hysterectomy could completely remove the infected tissues in severe cases.

In putrid infection the curette and tampon might relieve the patient, but in septic infection I do not believe such treatment is advisable, except it might be within one or two days after labor, where placental tissue has been left in the uterine cavity.

It is drainage and elimination we desire in these. cases, not obstruction. What surgeon of repute would tampon an abscess cavity through a very small opening without using a drainage-tube, letting the ganze remain two, three or four days, especially when there is a broken down tissue, débris and septic germs present in abundance.

After delivery nature establishes a process of elimination by a current flowing from the uterine cavity, the uterus and vagina being the main trunks of a sewer; the lymphatics, blood vessels, and uterine sinuses, its tributaries, obstruct the main channel, and what is the result? Who could think of filling the trunk sewer of a city with gauze and expect free drainage, even if done antiseptically after scraping out and flushing it? Yet we are advised to curette the uterus and fill it with gauze, damming up nature's channel of elimination, thus preventing the throwing off of effete material from the placental site, endometrium and lymphatics-obstructing the egress and retaining the phagocytes laden with germs and toxins, completely annulling phagocytosis, producing the very condition we should endeavor to prevent. Some will say only tampon after a thorough curetting: so much the worse, you have broken down and destroyed nature's barrier, opened up new surfaces for absorption, and favor that absorption by obstructing nature's method of elimination. I regret to say it, but it is my conviction that the curette and tampon indiscriminately used kill more patients than they save in septic infection.

Their indiscriminate usage manufactures cases for hysterectomy. In the treatment of these cases imitate nature as far as possible and establish a current of free drainage.

If any foreign substance is in uterus remove it with the forceps, wounding endometrium as little as possible; irrigate the uterine cavity thoroughly with an antiseptic solution and introduce as large-sized rubber drainage-tube as the os will admit. Repeat irrigations and cleansing of the drainage-tube at least once or twice in twenty-four hours. Do not neglect occasional use of salines and calomel if needed, with systematic use of quinin, strychnin, tonics, and good nourishing diet. Quinin certainly has a specific action in these cases in checking germ development and controlling the chills which accompany these cases. I venture to say that where this line of treatment is properly carried out it will save more lives. than the combined use of the curette, tampon, and hysterectomy. While I have in a great measure condemned hysterectomy in puerperal infection, I admit it has a limited field of usefulness in septic metritis, multiple abscesses in the uterine wall, thrombophlebitis, if it were possible for us to be positive in our diagnosis, but if in doubt I prefer drainage.

Unless future operative work gives better results. even this limited justification of hysterectomy may be abandoned.

In the above collection of cases I am satisfied, if the operation be limited strictly to severe cases of septic infertion, rapidly progressive and not in its secondary results, the death rate would be 80 or 90 per cent. of cases operated upon. Even a death rate of 50 per cent. is sufficient to condemn the operation. The proper use of the drainage-tube will not only save more lives, but the uterus, tubes and ovaries will be preserved for future usefulness and the sur. geon's conscience left more at ease.

\section{CASAREAN SECTION TWICE IN ONE PERSON.}

BY J. W. COAKLEY, M.D. IT. ETxa, IOWA.

August 3, 1893, I was called to see Mrs. P., aged 30 years, in her fourth pregnancy, there having been previously one abortion. I had performed craniotomy in two preceding labors on account of so great contraction of the pelvis that it was impossible for the child to be delivered, as the conjugate diameter was less than two and one-half inches.

It was difficult to assume the responsibility of the operation owing to opposition to it by elder members of the profession, as indeed it has been one of the most hazardous operations known until within the light of aseptic surgery. 